\title{
Logic Analysis of Painting Modeling Rules and Avoiding Narrative Viewing
}

\author{
Feng Zhu \\ School of Art and Design, Nanchang Hangkong University \\ No.696, Fenghenan Road, Hongjiaozhou, Honggutan New District \\ Nanchang 330063, China \\ E-mail: szfszfszf@hotmail.com \\ Jie Shao \\ School of Art and Design, Nanchang Hangkong University \\ No.696, Fenghenan Road, Hongjiaozhou, Honggutan New District \\ Nanchang 330063, China \\ E-mail: shaojie_juin@hotmail.com
}

\begin{abstract}
Painting modeling rules are constructed based on objective representing with material substances as the main body and the construction methods and orders are mostly limited to narrative viewing and expression, which, obviously, is not the best method. Logistic thinking in virtue of modeling art could gender a more "painting-like" cognitive order. The modeling elements extracted from dots, lines and planes lead us to the door for painting context and by way of personalized organization with explicit aims, we could be able to obtain "selective", "comparative", "holistic" and "sole" (creative) modeling and viewing principles.
\end{abstract}

Keywords: Modeling, Art logic, Painting context

Painting is the art of modeling. Researches on modeling rules directly guide viewing and expression in practicing process. Modeling is to create images while images are extracted from natural substances. Hence, extraction certainly involves selective acceptance and creative expression. Such selection and creation start from visual apperception, to understanding, to comprehending, to trans-translation and to expression and at the same time, involve various factors of modeling.

Visual apperception is mainly to view. The selectiveness of viewing is so obvious. A famous Chinese thinker wrote, "Blindmen touch elephant and describe the elephant differently. Then a man of good sight comes, what will he say?" It tells the selection and limits of blindman's apperception. Actually, man with good sight is not better. Different viewing angles, light environments, knowledge backgrounds and moods will bring different observation results. Although we consider all factors well, what "I" see may also be different from what "you" see. What is more important is that according to the main stream points of western modern philosophy, objects exist in our apperception and practices and co-exist with us. However, this kind of existence is not the existing objects but is non-real status. Besides, objects must have non-real status freedom; we apperceive various information of objects while "objects" are always more than the contents that we have apperceived. We just apperceive selectively; in addition, when we use drawing to describe our apperception, we have to depend on our experience and drawing language (signifier), which is greatly different from the signified that we want to express.

Since we could not, to an absolute sense, grasp the "object" in apperception and could not control the final results of the receiving of art creation with painting as the carrier, we shall not have too many expectations on it. For works, it is pretty good if they could express their basic connotations. The core problem lies in whether what we intend to say could deeply impress the audiences.

To put it simply, assume that we are describing a weary character image. We choose a model named "W" who is sloven, bald, and crookbacked. Firstly, these features that we apperceived testify the existence of "W", however, obviously, "W" is not the features or even it is not the man named "Zhangsan". It is just the name we call him. Visually, the real W is just the collection of "objects" believed to be male. It is not necessary for us to find all his features and we only need to describe his weary image. When modeling, we just need to find and grasp relevant features. The next time when we need to describe a happy image, if we still have this model, we also just need to grasp some other features of this model.

Certainly, to achieve this kind of selective extraction in modeling, we must change our traditional viewing methods and the first step is to learn to view with painting elements as the fiducial line. That is:

\section{What we shall view and what we see?}

Usually, people will choose the following two viewing ways. They are not "space" or "holistic". 


\subsection{Serial viewing from single dimension}

To view by way of linear narration is the normal status when we observing objects. For example, when we are observing a bottle, if some one has not accepted training on it, he or she will use the language narrative elements as the organizing method, such as bottle cover, bottle neck, bottle body, label and bottom. When describing, they also will follow this organizing method. The apperception process is also influenced, customarily, by top-down and left-right alignment ways. Generally speaking, any artistic category could not lapse from narrative elements. Language and words are just the main methods fro narration while others, such as painting and music, also need the complements of narrative elements. However, to put control on it and to avoid it under appropriate circumstances is also necessary, which is not just the needs for keeping their artistic pureness but also is the results of the establishment of development of their professional contexts.

\subsection{Infatuated viewing}

Infatuated viewing is a viewing method with immense individual emotions. Mostly, painting beginners usually use this kind of method. They pay special attention to colorful or detailed section. It is the same as when we watch a movie because we like the star in it rather than the movie itself. We could call it fans complex, which is also a common phenomenon among art lovers. The better viewing method is holistic and comprehensive viewing, which could help painters to control subjectively and to represent objectively. This is the most obvious psychological difference of art creation and appreciation on description objects.

The aim of modeling training is to break through this kind of unprofessional observation ways and to teach painters to use painting observation method, which is shown as follows:

Narrative elements are replaced by modeling elements. It starts from dots, the positions of dots, and the distances and angles and space orders among dots; ant then is the observation and comparison of lines and faces, involving length, thickness, inclination, sizes and colors and etc.

The holistic control over the painting forms focuses orders with clear aims. It usually starts from the division of the entire painting. The object is holistically shown by way of groups. Firmness, emptiness or hardness are compared according to regions and are apperceived and represented.

Subjective intention judgment will control the viewing contents and representation methods, which is to selectively apperceive among the many objects.

When your eyes are full of distances, proportions or extended angles, the object images will be lost in these abstractions and the painting picture will become dim and unsure. It will be hard for find the specific object images such as label or eyebrow. When we lose narrative logistic, we get the complement from modeling artistic logic and hence enter painting context. From some extent, it realizes the demand of traditional painting theory "mountain is not mountain in the eyes".

\section{Methods and training on painting picture construction}

If the narrative logistic is broken, the organization way that description depends on does not exist either. Then what should we depend on to organize painting picture? How to determine what be drawn first and what the next? How to determine what is the main or second painting picture elements?

Two comparatively simple organization ways are listed below for reference.

\subsection{Painting picture organization practice based on negative shape}

Negative shape refers to the non real shapes generated from the interlacing of positive objects. Before, people use it to check whether the shape is correct with negative shape as an auxiliary method. Currently, it is required to pay attention to the painting picture form structure brought by negative shapes and take it as the organization elements fro painting picture so as to have holistic observation and imaginary observation and to solve the problem of the lose of painting organization way when language narrative elements are broken.

\subsection{Painting picture organization practice based on channel}

The aim of this practice is also for solving the losing of organization way. If negative shape concept is limited to plain status, the channel concept is the cubic extension of negative shape concept. For example, we could imagine the cracks among objects as rivers among mountains. When we describe these mountain rivers, we usually will not require the integrity of mountains. As an understanding of negative space, its sense is extremely the same as channel. Therefore, we will ask in the process of detailed description (such as scene or static objects), could he channel sense brought by the cracks among objects become the theme of the painting?

When the construction ways is clear, the new logistic relationship among objects, pictures and objects, souls and expression is established, which is totally different from narrative logic. We attribute it to the special art logic of modeling art. When we need to show certain theme, artistic logic thinking method will lead the eyes to view selectively. The special modeling requirement of this theme will become the tache of the painting, eventually form systematical expression for the theme, and realize the visual allusion and metaphor function of modeling to the utmost so as to 
arouse psychological apperception and emotional resonance of the art receivers.

\section{The formation of transformation and abstraction}

We have fixed the object-for-our-use modeling and viewing principle. Painting is not to mechanically represent objects. For theme, the object shapes in the works could be cut or transformed for certain needs. Even, the space could be freely extended according to the demands of the painters. A typical case could be found in Cézanne's works. To emphasize the connection between sky and mountains and to enlarge the color difference, Cézanne put the sky closed to the mountain top. At the same time, through several geometric shapes' operation, Cézanne combined multi-angle contents into one picture. This kind of method enlarges and enriches our visual cognition on the nature and changes traditional aesthetic rules.

What needs to be complemented is that when entering painting context, we also find the cut-in point of abstract concepts. The said abstraction means to abstract some common elements from objects (all modeling painting elements could certainly be taken as abstract element) and to do research and find rules so as to have further creation. When we could freely treat the specific objects in the process of painting and the objects are all for our use, we obtain the modeling freedom beyond objects.

The real result to construct new picture orders is to find independent and individual picture orders according to the real conditions of the objects and painters so as to master the key picture structures and realize diverse observation painting angles. Because the new picture orders are obtained through the logic reasoning of natural objects, it could certainly be understood and appreciated by viewers. When people understand and accept the special observation method, they realize the jump of "mountains are still mountains in the eyes". The "mountains" here are not the original image of mountains but rather the thoughts carrier and reference tools abstracted by the painters.

\section{Replace painstaking with writing and reinforce the emotional expression of the creation body}

Modeling logic could not be parted from creation emotion. We encourage to replace painstaking with writing due to avoiding narrative expression in art practice. Each one's writing will be different due to his personality, experience and environment. These differences will represent the personality, hobbies and creation emotions of painters, which will to the utmost transfer the works' connotation and art sense through pictures so as to move viewers and achieve resonance.

As the opposite of writing, painstaking refers to tidiness and time spent. A good works will take the painters' lots of time so as to be orderly. However, if a works is too orderly, it will lose the elf sense of art works and will be reduced to works easy to be duplicated. Its creation connotations will also become the simple narration of structure and plots. There forms a theory opposed to traditional narration logic. For one hand, we need to carefully observe and draw and be special in creative representation; for another hand, we need to hide this hard skill behind when representing works. The emotions of painters should be natural without tracks when transferring emotion to receivers. Works that consumer painter's too much energy to draw and viewers' too much time to understand will, to the most, become a good works and could not break through to become the best works.

To reinforce the emotional expression of creation bodies has always been popular in eastern painting field. Traditional Chinese painting emphasizes painting meanings. It pursues soul similarity in modeling, human science character in spirit, and not-so-open creation emotions. Western traditional painting emphasizes painting reality. The art emotions are hidden in works. Personalized writing touch and emotional revealing are mainly shown from the post-impressionism, hot abstractionism to other schools. In sculpture works, the carve tracks are gradually reinforced and they purse open and obvious visual force and creation emotions. The drawing full of writing sense is closely related to creation emotions. When bring moves to the works, it also contains the painter's cognition and apperception of art space relationship. Up to now, most modern painters could consciously avoid narrative elements, which reinforces the representation pureness of art works and improves the meaning-expressing ability and inner characters of works.

\section{References}

Cézanne ,Paul's works, Saint-Victoire

Points for Heidegger, Hegel, and Saussure

Zhu, Feng \&Shao, Jie. (2008). Vision logic and aesthetic evolution. Asian social science, edition 11.

Zhu, Feng \&Shao, Jie. (2008). Art logistic thinking over color pureness and richness degree; Art logistic thinking over color richness degree and color materials. Art Field, edition 8 and 9.

\section{Notes}

This paper is of sub-thesis paper of Logistic Analysis of Modeling Basic Rules and Multi-dimensional Radiation Teaching Communication, the general subject numbering 105 of 2008 jiangxi Provincial Education Science

“Eleventh Five Years” Plan Subjects. 